\title{
\begin{tabular}{l|l} 
Mitraries & DSpace@MIT
\end{tabular}
}

\author{
MIT Open Access Articles
}

\section{Atomic Structure and Dynamics of Single Platinum Atom Interactions with Monolayer MoS}

The MIT Faculty has made this article openly available. Please share how this access benefits you. Your story matters.

Citation: Li, Huashan, et al. “Atomic Structure and Dynamics of Single Platinum Atom Interactions with Monolayer MoS2." ACS Nano 11, 3 (March 2017): 3392-3403 (c) 2017 American Chemical Society

As Published: http://dx.doi.org/10.1021/ACSNAN0.7B00796

Publisher: American Chemical Society (ACS)

Persistent URL: http://hdl.handle.net/1721.1/114821

Version: Author's final manuscript: final author's manuscript post peer review, without publisher's formatting or copy editing

Terms of Use: Article is made available in accordance with the publisher's policy and may be subject to US copyright law. Please refer to the publisher's site for terms of use. 


\title{
Atomic Structure and Dynamics of Single Platinum Atom Interactions with Monolayer $\mathrm{MoS}_{2}$
}

\author{
Huashan Li, ${ }^{\dagger, \perp}$ Shanshan Wang, ${ }^{\dagger, \perp}$ Co Hidetake Sawada, ${ }^{\ddagger, \S, \|}$ Grace G. D. Han, ${ }^{\dagger}$ Thomas Samuels, ${ }^{\dagger}$
} Christopher S. Allen, ${ }^{+, \| l}$ Angus I. Kirkland, ${ }^{\ddagger}, \|$ Jeffrey C. Grossman, ${ }^{* \dagger}$ and Jamie H. Warner,

\author{
${ }^{\dagger}$ Department of Materials Science and Engineering, Massachusetts Institute of Technology, 77 Massachusetts Avenue, Cambridge, \\ Massachusetts 02139, United States \\ ${ }^{\ddagger}$ Department of Materials, University of Oxford, Parks Road, Oxford, OX1 3PH, United Kingdom \\ § JEOL Ltd., 3-1-2 Musashino, Akishima, Tokyo 196-8558, Japan \\ "Electron Physical Sciences Imaging Center, Diamond Light Source Ltd, Didcot, Oxfordshire, OX11 0DE, United Kingdom
}

\author{
Supporting Information
}

\begin{abstract}
We have studied atomic level interactions between single $\mathrm{Pt}$ atoms and the surface of monolayer $\mathrm{MoS}_{2}$ using aberration-corrected annular dark field scanning transmission electron microscopy at an accelerating voltage of $60 \mathrm{kV}$. Strong contrast from single Pt atoms on the atomically resolved monolayer $\mathrm{MoS}_{2}$ lattice enables their exact position to be determined with respect to the $\mathrm{MoS}_{2}$

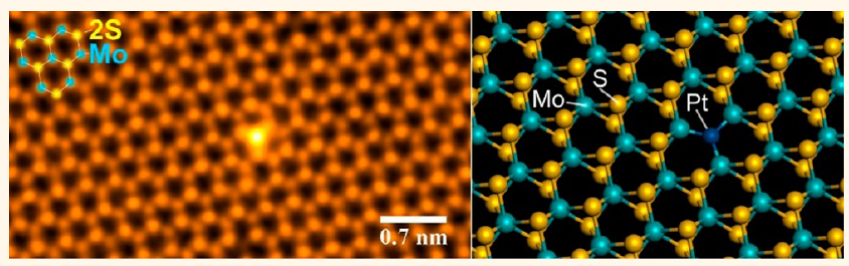
lattice, revealing stable binding sites. In regions of $\mathrm{MoS}_{2}$ free from surface contamination, the $\mathrm{Pt}$ atoms are localized in $\mathrm{S}$ vacancy sites and exhibit dynamic hopping to nearby vacancy sites driven by the energy supplied by the electron beam. However, in areas of $\mathrm{MoS}_{2}$ contaminated with carbon surface layers, the $\mathrm{Pt}$ atoms appear at various positions with respect to the underlying $\mathrm{MoS}_{2}$ lattice, including on top of Mo and in off-axis positions. These variations are due to the $\mathrm{Pt}$ bonding with the surrounding amorphous carbon layer, which disrupts the intrinsic $\mathrm{Pt}-\mathrm{MoS}_{2}$ interactions, leading to more varied positions. Density functional theory (DFT) calculations reveal that Pt atoms on the surface of $\mathrm{MoS}_{2}$ have a small barrier for migration and are stabilized when bound to either a single or double sulfur vacancies. DFT calculations have been used to understand how the catalytic activity of the MoS ${ }_{2}$ basal plane for hydrogen evolution reaction is influenced by Pt dopants by variation of the hydrogen adsorption free energy. This strong dependence of catalytic effect on interfacial configurations is shown to be common for a series of dopants, which may provide a means to create and optimize reaction centers.
\end{abstract}

KEYWORDS: Pt dopants, $M o S_{2}$ ADF-STEM, 2D materials, catalysts, dopants

$\checkmark$ he presence of single isolated atom impurities and dopants either on the surface or directly bonded within the lattice structure of $2 \mathrm{D}$ materials influences the properties. ${ }^{1-10}$ Understanding the atomic structure that defines the bonding between single foreign atoms and the host $2 \mathrm{D}$ crystal is critical for developing accurate models that can predict the impacts of doping. Single metal atom doping of materials has also found significant recent interest in the development of catalysts by reducing the mass content of precious metals such as $\mathrm{Pt}$, while maintaining high performance. ${ }^{11-13} \mathrm{~A}$ key aspect to single metal atom catalysts is preventing aggregation of the active species into clusters, reducing the loss of metal atoms by detachment, and providing the optimum bonding configuration for catalytic activity. Recent work has shown that doping $2 \mathrm{D}$ layered $\mathrm{MoS}_{2}$ can lead to higher activities in the hydrogen evolution reaction, utilizing $\mathrm{Co}, \mathrm{Ni}$, and $\mathrm{Pt}$ single-metal dopants. ${ }^{14,15} \mathrm{MoS}_{2}$ is normally active only at edge sites, but the incorporation of isolated metal substitutional or surface dopants can activate the basal plane and lead to a large increase in the number of active catalytic sites. Therefore, resolving the atomic structure of single metal atoms and their structural interaction with $\mathrm{MoS}_{2}$ helps reveal the stable configurations that dictate the catalytic performance.

Aberration-corrected electron microscopy (AC-TEM), in both phase contrast TEM (AC-TEM) and annular dark field scanning transmission electron microscopy (ADF-STEM) modes, has been shown to be a key method for directly imaging single-metal dopants in nanoscale materials. When combined with electron energy loss spectroscopy (EELS) it is

Received: February 5, 2017

Accepted: February 27, 2017 


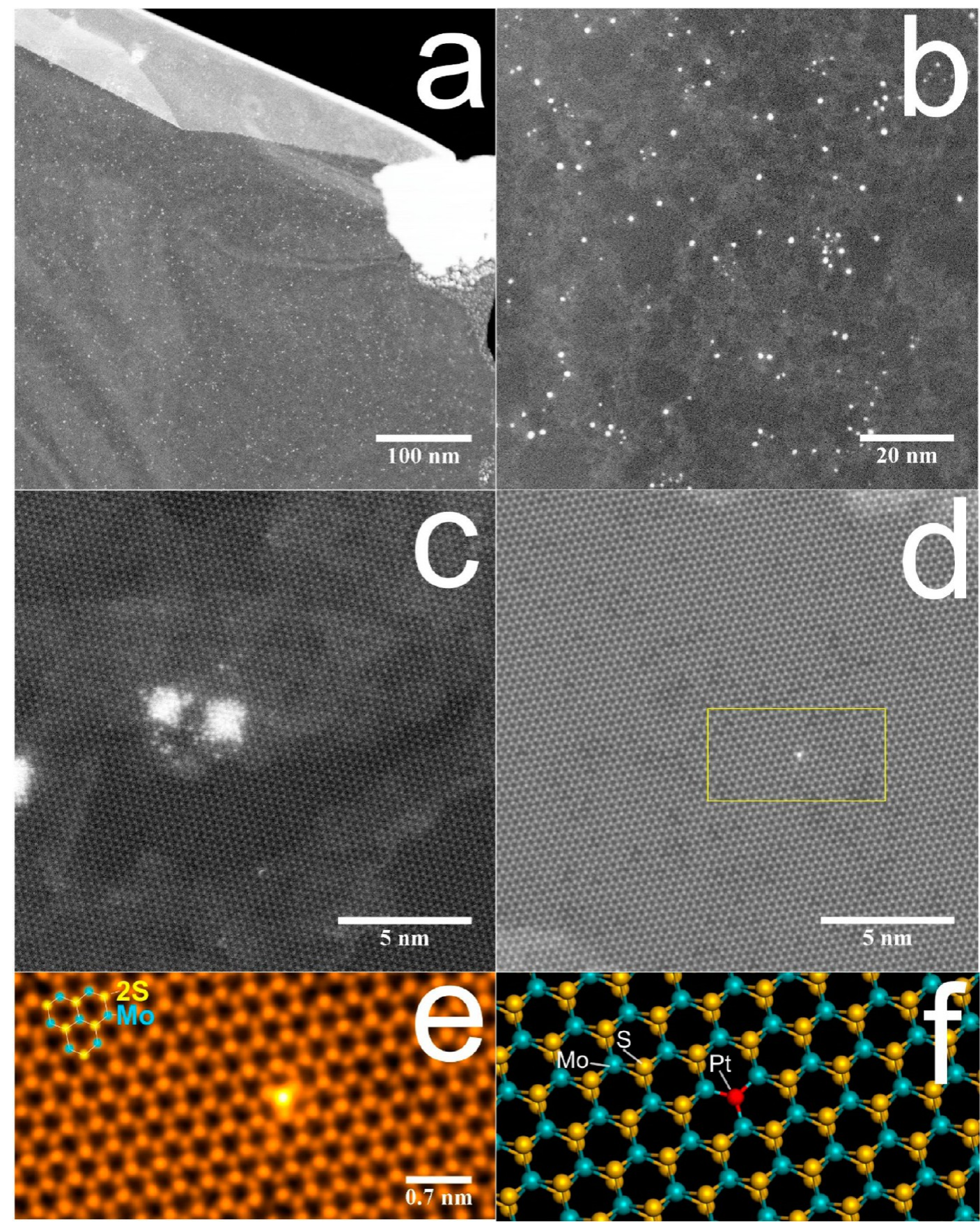

Figure 1. ADF-STEM images of Pt on monolayer $\mathrm{MoS}_{2}$. (a) Low-magnification image showing Pt nanoparticles on the surface of MoS ${ }_{2}$ (b and c) Higher magnification images showing Pt nanoclusters and single Pt atom species on the surface of $\mathrm{MoS}_{2}$. (d) Atomic resolution image showing a single Pt atom located in the clean region of $\mathrm{MoS}_{2}$. (e) Enlarged image from the boxed region in (d) (orange false color), showing strong contrast from a single Pt atom located in a $S$ lattice site. (f) DFT relaxed atomic model showing a Pt atom in a $2 S$ vacancy site.

possible to map elemental composition at the single-atom level. $^{16-18}$ The $z$-dependent contrast in ADF-STEM results in bright contrast at heavy single metal atom sites, such as $\mathrm{Au}$, on the surface or within the lattice of lighter elemental materials such as graphene or $\mathrm{MoS}_{2} \cdot{ }^{19} \mathrm{Au}$ atoms on the surface of $\mathrm{MoS}_{2}$ have been observed on a range of atomic sites, such as on top of S, Mo, and hollow sites. ${ }^{19}$ Recent work using ADF-STEM and EELS has further revealed that $\mathrm{Cr}$ and $\mathrm{V}$ dopants are often present in chemical vapor deposition (CVD)-grown $\mathrm{MoS}_{2}$, where the $\mathrm{Cr} / \mathrm{V}$ dopants directly substitute Mo atoms. ${ }^{20,21}$

The surface of $2 \mathrm{D}$ materials such as graphene and $\mathrm{MoS}_{2}$ typically contains patches of amorphous carbon, and this modifies the local surface chemistry. Deposition of metal atoms onto graphene results in preferential adhesion to the amorphous region, which makes it difficult to study intrinsic 2D-metal interactions. Recent work using in situ hightemperature heating in AC-TEM to remove the amorphous carbon residue to study the epitaxial interactions between gold nanoclusters and graphene has shown different behavior compared to amorphous carbon surfaces. ${ }^{22}$ Extending this approach to the single-atom level in a variety of $2 \mathrm{D}$ materials will reveal insights into single-metal atom behavior for a diverse range of applications, including photonics and catalysis with $\mathrm{MoS}_{2}$. For $\mathrm{MoS}_{2}$ monolayers, amorphous surface carbon will be 

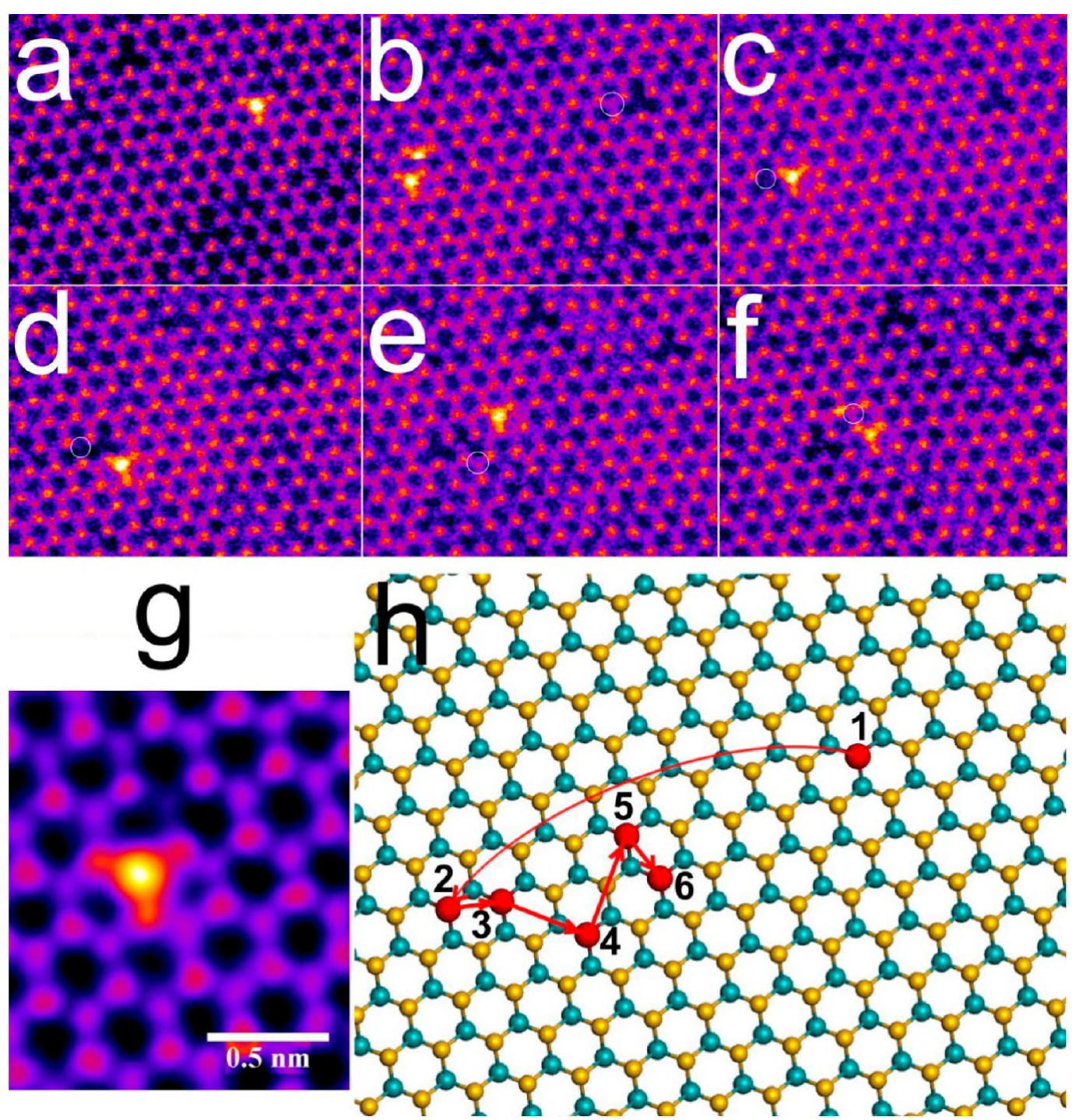

Figure 2. Dynamics of Pt atom migration across the surface of $M_{2} \cdot(a-f)$ Sequence of ADF-STEM images (false color LUT "fire") capturing the movement of a single Pt atom on $\mathrm{MoS}_{2}$. White circles indicate the prior location. (g) Magnified ADF-STEM image of the Pt atom in (a), showing the $\mathrm{Pt}$ sitting in the $\mathrm{S}$ site location and the presence of a $\mathrm{S}$ vacancy. (h) Schematic illustration of $\mathrm{Pt}$ migration on a MoS $\mathrm{Surface}_{2}$

hard to image against the $\mathrm{MoS}_{2}$ layer. However, using ADFSTEM at a lower accelerating voltage of $60 \mathrm{kV}$ should enable contrast differentiation between clean and contaminated regions and hence enable imaging of single metal atom dopant structure in each of these regions. Many of the studies have involved metal dopants incorporated at the synthesis stage, rather than postsynthesis deposition. Clear unambiguous atomically resolved structure of single $\mathrm{Pt}$ atoms on the surface of clean $\mathrm{MoS}_{2}$ has yet to be achieved, where both $2 \mathrm{~S}$ and Mo columns are discriminated, $S$ vacancies are identified, and the detailed Pt bonding to the $\mathrm{MoS}_{2}$ is evident in the images. Such information will help further understanding of this hybrid system for future catalytic applications.

Here, we have used monolayer $\mathrm{MoS}_{2}$ grown by CVD as an ideal clean transition metal dichalcogenide (TMD) substrate to deposit a Pt precursor from solution to form a hybrid $\mathrm{Pt}-\mathrm{MoS}_{2}$ system and to study the detailed atomic structure of the species formed using ADF-STEM at an accelerating voltage of $60 \mathrm{kV}$ to minimize $S$ vacancy production. $S$ vacancies are still produced, but at a lower rate than at higher voltages. We have located single $\mathrm{Pt}$ atoms in both clean and carbon-contaminated regions of $\mathrm{MoS}_{2}$ and have directly resolved the atomic structure of the $\mathrm{Pt}$ binding sites relative to the $\mathrm{MoS}_{2}$ lattice. Dynamics of $\mathrm{Pt}$ diffusion across the clean $\mathrm{MoS}_{2}$ surface have been captured at room temperature, where energy is supplied by the electron beam. Comparisons of the site location of $\mathrm{Pt}$ atoms in these two regions show that $\mathrm{Pt}$ on clean $\mathrm{MoS}_{2}$ is positioned at $\mathrm{S}$ sites, whereas $\mathrm{Pt}$ in contaminated carbon regions is located at random sites relative to the $\mathrm{MoS}_{2}$ lattice. This is due to $\mathrm{Pt}-\mathrm{C}$ bonding, which influences the structure, compared to the clean $\mathrm{MoS}_{2}$ region, where intrinsic Pt surface migration dominates. Density functional theory (DFT) calculations of the relative binding energies of $\mathrm{Pt}$ to different sites on the surface of $\mathrm{MoS}_{2}$ show that $S$ vacancies are required to trap $\mathrm{Pt}$ in a location. While trapped $\mathrm{Pt}$ atoms tend to suppress the activity of $\mathrm{S}$ vacancy, Pt dopants on a defect-free $\mathrm{MoS}_{2}$ sheet may serve as catalytic centers for hydrogen evolution reaction (HER).

\section{RESULTS AND DISCUSSION}

Monolayer $\mathrm{MoS}_{2}$ grown by CVD was transferred to a SiN TEM grid using a poly(methyl acrylate) (PMMA) support layer and cleaned by thermal annealing. Small thin residual carbon 
patches found on the $\mathrm{MoS}_{2}$ are most likely from the PMMA. After initial AC-TEM inspection to ensure the sample was free from a substantial carbon contamination and had significant regions of pristine $\mathrm{MoS}_{2}$ visible, a drop of Pt precursor solution was deposited onto the grid and allowed to dry in air. The sample was then heated under Ar gas flow at $350{ }^{\circ} \mathrm{C}$ to decompose the Pt precursor and produce $\mathrm{Pt}$ on the surface of $\mathrm{MoS}_{2}$. Some of the Pt had aggregated into small nanoclusters, Figure $1 \mathrm{a}-\mathrm{c}$, and energy dispersive X-ray spectroscopy confirmed they contain Pt, Figure S6. There are also individual Pt atoms distributed across the sample and some few-atom clusters, Figure S2. Some of the isolated Pt atoms adhered to the surface amorphous carbon, which is visible with higher contrast in Figure $1 \mathrm{~b}$ and c. Figure S1 also shows Pt atoms bound to carbon contamination regions. However, $\mathrm{Pt}$ atoms are also found in the pristine regions of $\mathrm{MoS}_{2}$, away from the amorphous carbon regions, as shown in Figure 1d.

The ADF-STEM image shown in Figure le is a magnified view from the yellow boxed region in Figure 1d, showing a single $\mathrm{Pt}$ atom on $\mathrm{MoS}_{2}$. Contrast in an ADF-STEM image is larger for higher atomic number elements/columns, enabling the discrimination of the Mo and $2 \mathrm{~S}$ columns in the $\mathrm{MoS}_{2}$ image in Figure 1e, which shows a $\mathrm{Pt}$ atom located in a $\mathrm{S}$ column site. We have imaged more than 10 individual Pt atoms residing in the clean areas of $\mathrm{MoS}_{2}$, and all showed the same structure of $\mathrm{Pt}$ atoms located in S sites. Figures S4 and S5 show two more examples. The atomic model in Figure if shows a schematic $3 \mathrm{D}$ view of a $\mathrm{Pt}$ atom replacing two $\mathrm{S}$ atoms, i.e., located at a $2 S$ vacancy (2S-sub configuration).

ADF-STEM imaging at an accelerating voltage $60 \mathrm{kV}$ of the single $\mathrm{Pt}$ atom (Figure $1 \mathrm{~d}$ and e) caused migration across the surface of $\mathrm{MoS}_{2}$ before being trapped at other sites for fixed durations, with energy supplied from the electron beam. Figure 2 shows a sequence of ADF-STEM images in which the hopping of a single Pt atom to five different sites is observed, all of which are $S$ lattice sites, further confirming the preference for $\mathrm{Pt}$ to bind to $\mathrm{S}$ positions rather than Mo sites on a clean surface. The apparent double image of a Pt atom in Figure $2 \mathrm{~b}$ is due to the electron beam causing the $\mathrm{Pt}$ to hop during the raster scanning image formation process. Small white circles are used to indicate the Pt atom's prior position. This type of dynamics is typical for atomic scale systems imaged by TEM, where we capture only the positions of fixed stability between the rapid motion. Figure $2 \mathrm{~g}$ shows a smoothed magnified image of the $\mathrm{Pt}$ atom from Figure $2 \mathrm{a}$, showing the $\mathrm{Pt}$ sits at the $\mathrm{S}$ site, but also the presence of a $S$ vacancy to the top right, evident by the reduced contrast. Figure $2 \mathrm{~h}$ shows the migration of the $\mathrm{Pt}$ atom schematically illustrated on a $\mathrm{MoS}_{2}$ lattice, revealing a random direction, even though the electron beam is scanning. Further insights into this dynamic behavior are gained by using density functional theory to calculate the energy barriers for migration of $\mathrm{Pt}$ atoms on the surface of $\mathrm{MoS}_{2}$.

Image simulations, Figure $3 \mathrm{e}-\mathrm{g}$, were performed based on DFT relaxed atomic models, Figure $3 \mathrm{a}-\mathrm{c}$, and were compared to an experimental ADF-STEM image of Pt on $\mathrm{MoS}_{2}$, Figure 3d. Line profiles, Figure 3i, show a good contrast match between the experimental image in Figure $3 \mathrm{~d}$ and the simulation of a $\mathrm{Pt}$ atom in the $2 \mathrm{~S}$ vacancy, Figure $3 \mathrm{c}$ and $\mathrm{g}$. The contrast in the image simulations and experimental images was normalized to that in the Mo column. The contrast from the $\mathrm{Pt}$ region is substantially less than that predicted from simulations for $\mathrm{Pt}$ on top of $2 \mathrm{~S}$ atoms. Analysis of the ADFSTEM contrast signals for four different $\mathrm{Pt}$ atoms in $\mathrm{S}$ vacancy

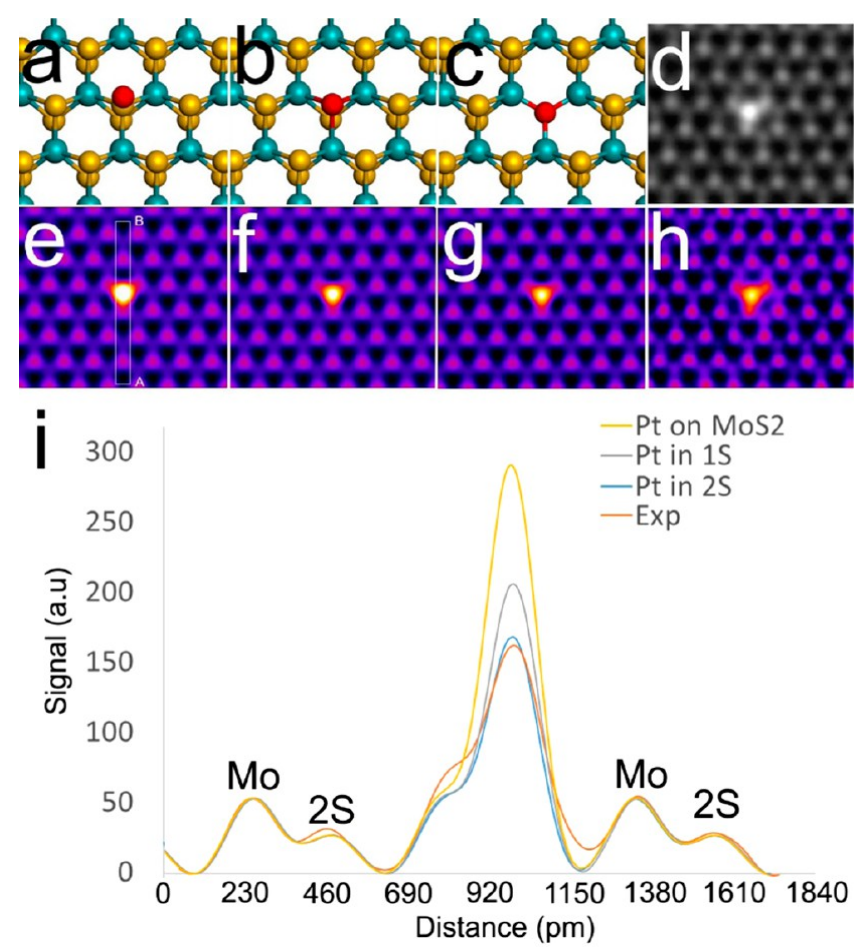

Figure 3. Image simulations of the $\mathrm{Pt}$ atom in different configurations. (a-c) Atomic models for (a) Pt on top of 2S, (b) $P t$ in a $1 S$ vacancy, and (c) Pt in a $2 S$ vacancy. Tilt is introduced to show the $2 S$ atoms. (d) Experimental ADF-STEM image of a Pt atom on $\mathrm{MoS}_{2}$ in grayscale. (e-g) ADF-STEM image simulations based on the models shown in $(a)-(c)$, respectively. Color LUT "fire" is used to highlight the contrast associated with the Pt atom. (h) Processed image from (d) with color LUT "fire" used for comparison to image simulations. (i) Boxed line profiles taken from the grayscale images of $(e)-(h)$, respectively, across the region indicated by the white box in (e) from the $A-B$ direction. Plots are normalized to the Mo column intensity for relative comparison.

sites (Figure S7) showed two matched $\mathrm{Pt}$ in $1 \mathrm{~S}$ and two matched $\mathrm{Pt}$ in $2 \mathrm{~S}$. Therefore, we conclude that the $\mathrm{Pt}$ is residing within both $1 S$ and $2 S$ vacancy defects in the ADF-STEM images.

The energy barrier for a $\mathrm{Pt}$ atom to migrate across the surface of pristine $\mathrm{MoS}_{2}$ is calculated in Figure 4, for two different pathways, by the valley site (V-top Figure $4 a-d$ ) or by the $S$ atom (S-top Figure $4 \mathrm{e}-\mathrm{h}$ ). Both pathways have small DFT energy barriers of $\sim 0.6-0.82 \mathrm{eV}$, which indicates that Pt atoms can diffuse easily across the surface of defect-free $\mathrm{MoS}_{2}$ at room temperature. Binding energies were calculated by DFT for Pt at the following sites: $\mathrm{S}$-top $=3.22 \mathrm{eV}$, Mo-top $=3.71 \mathrm{eV}$, and $\mathrm{V}$ top $=3.17 \mathrm{eV}$. However, the energy barrier for migration is significantly different if the $\mathrm{Pt}$ atom is located within a $\mathrm{S}$ vacancy (S-sub).

Figure 5 shows the energy barriers needed for a Pt atom to escape from a single $S$ vacancy to the $M_{0} S_{2}$ surface by three different pathways, Mo atom (Figure 5b), V-top (Figure 5c), and S-top (Figure 5d). All pathways show similar escape energy barriers of $\sim 3 \mathrm{eV}$ and small barriers $(<0.5 \mathrm{eV})$ for backward hopping, leading to an extremely large imbalance between forward and backward transitions (rate ratio $>10^{45}$ based on the Arrhenius equation), which indicates that the presence of the $S$ vacancy in $\mathrm{MoS}_{2}$ acts as a stable trapping site to localize $\mathrm{Pt}$ atoms. This also supports the experimental observations in 

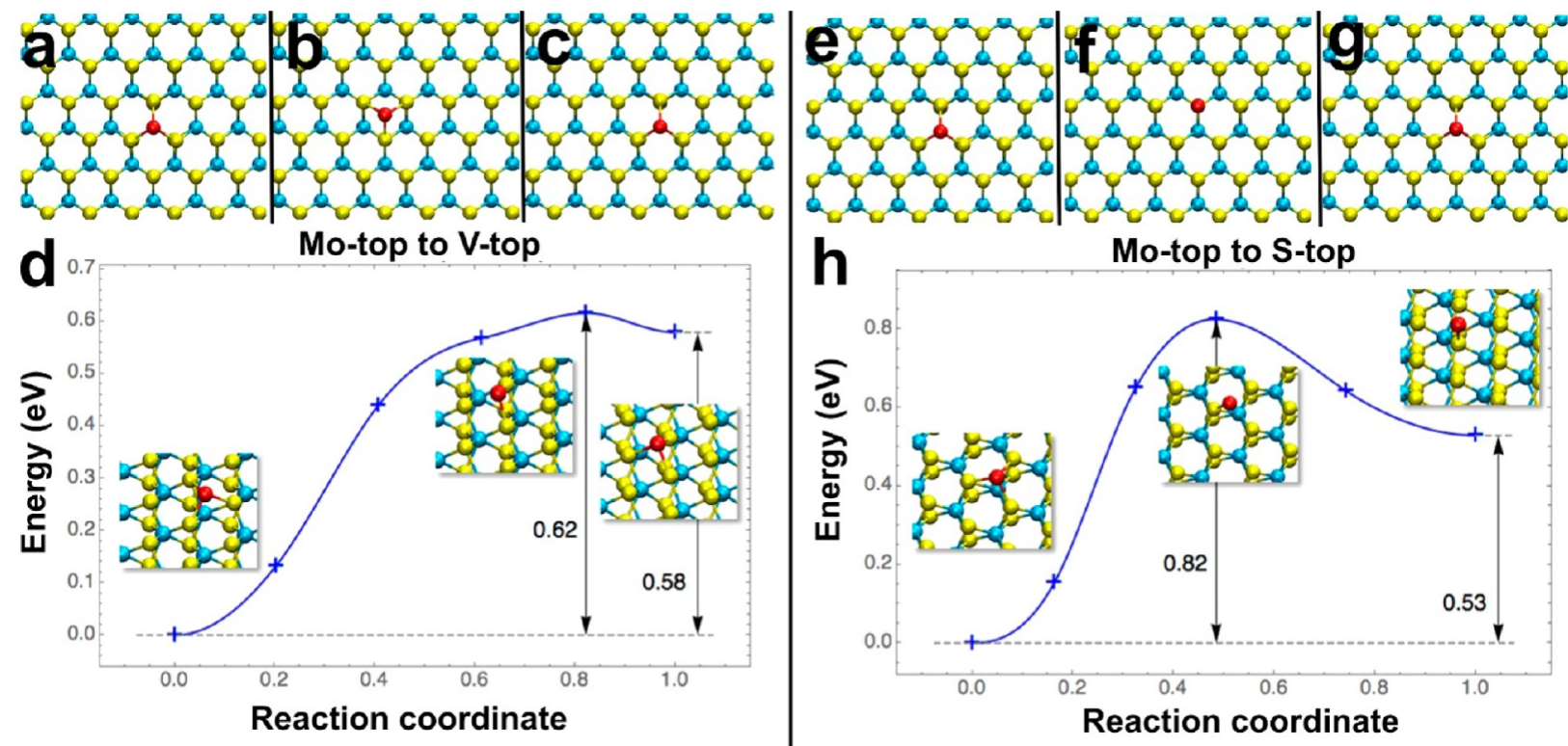

Figure 4. DFT calculations for a single Pt atom migrating across a pristine $\mathrm{MoS}_{2}$ surface for two different pathways. (a-c) Mo-top site to valley site (V-top) to Mo-top site. (d) Energy as a function of reaction coordinate for pathway (a) -(b). (e-g) Mo-top site to S-top site to Motop site. (h) Energy as a function of reaction coordinate for pathways (e)-(f).
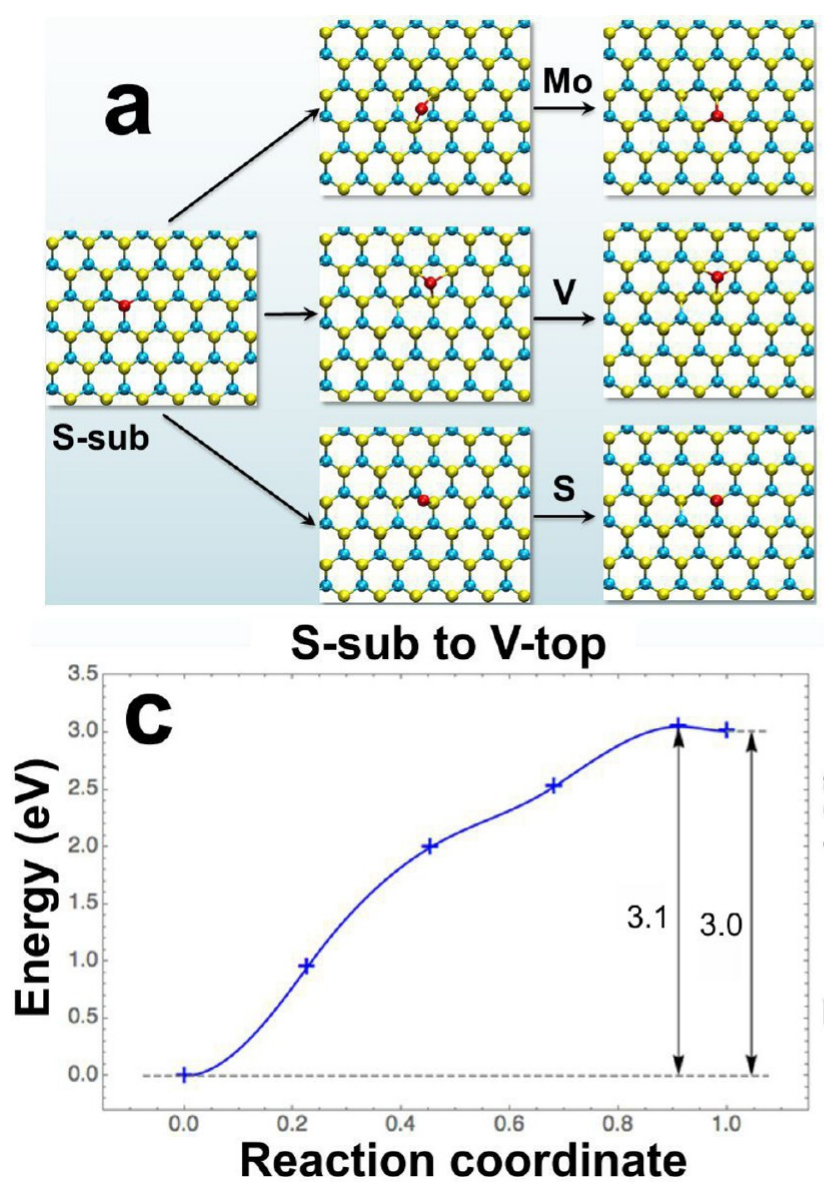

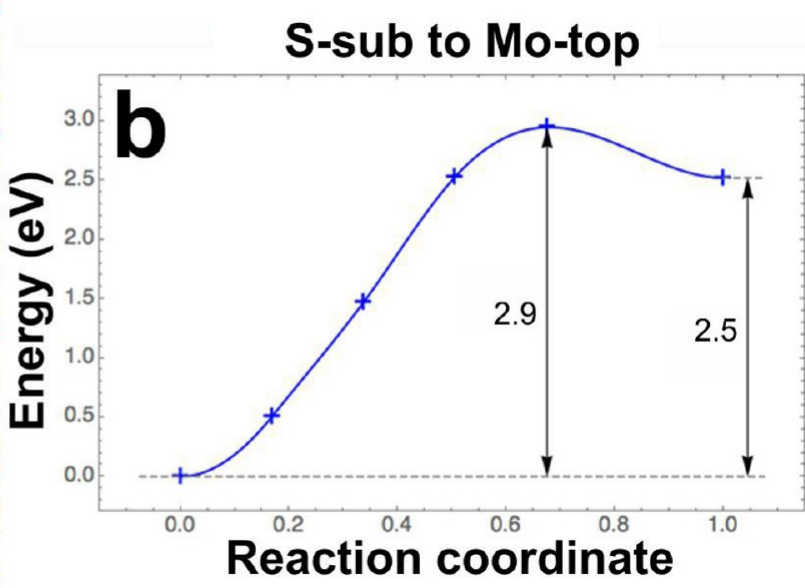

S-sub to S-top

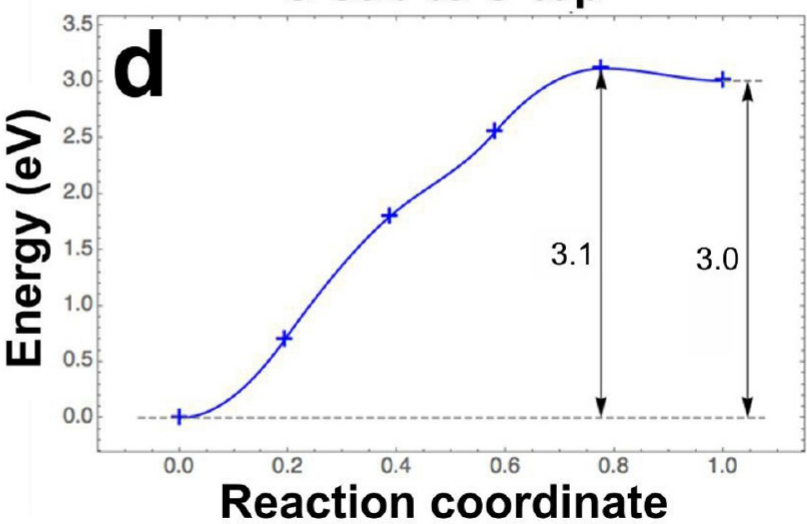

Figure 5. DFT calculations for a single Pt atom escaping from a $S$ vacancy across the $M_{0} S_{2}$ surface for three different pathways. (a) By Mo-top site, V-top site, and S-top site. (b) Energy as a function of reaction coordinate for the Mo-top site pathway. (c) Energy as a function of reaction coordinate for the V-top site pathway. (d) Energy as a function of reaction coordinate for the S-top site pathway.

Figures 1 and 2, where $\mathrm{Pt}$ is predominantly observed in the $\mathrm{S}$ site. Given that a monosulfur vacancy is much more abundant than a disulfur vacancy, ${ }^{23}$ the reaction paths and catalytic properties were calculated only for the S-sub configuration. Nevertheless, the same behavior is expected for $\mathrm{Pt}$ in a $2 \mathrm{~S}$ vacancy (2S-sub), which exhibits a similar structure with a 

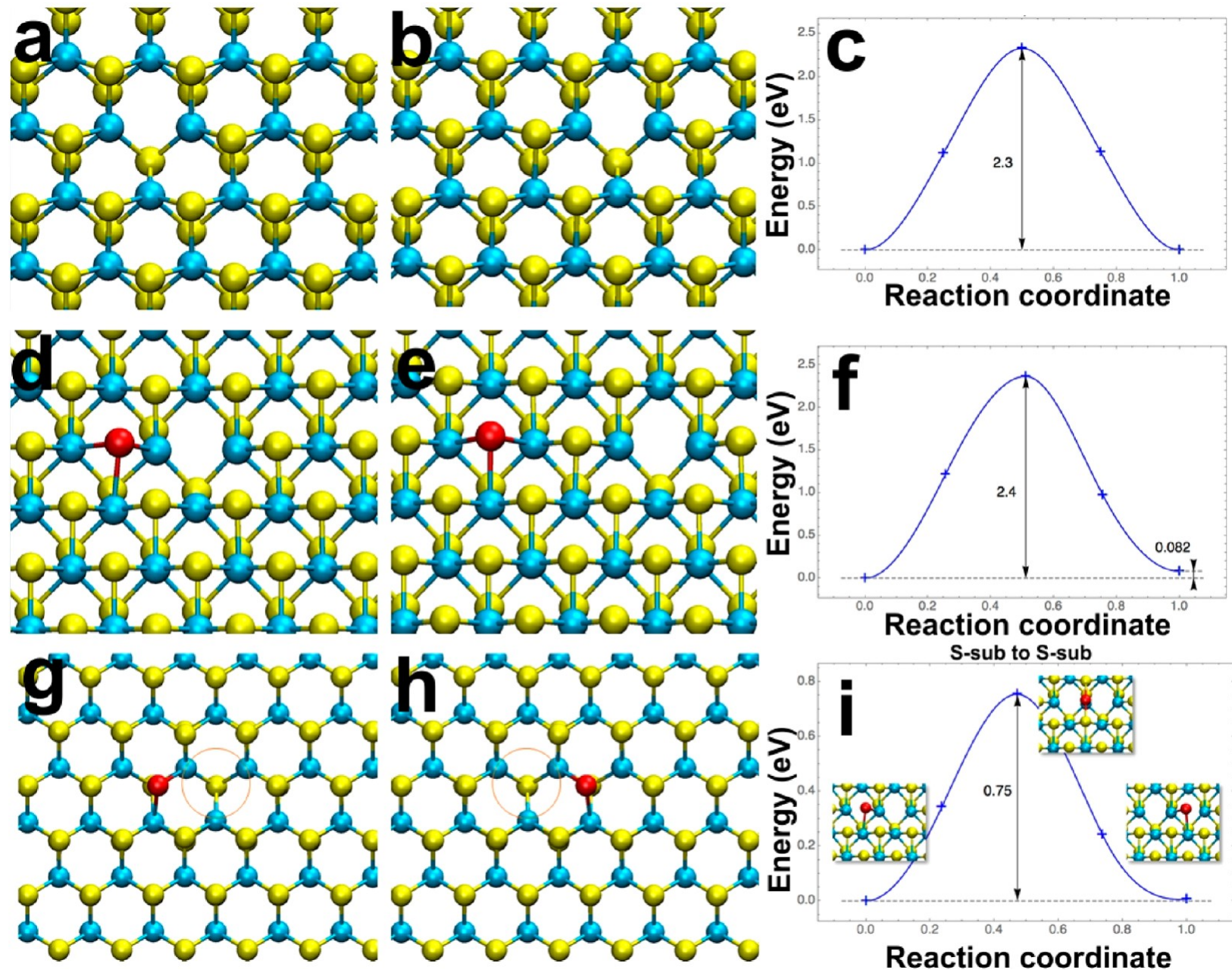

Figure 6. DFT calculations for $S$ vacancy migration and $\mathrm{Pt}$ migration with $\mathrm{S}$ vacancy assistance. (a, b) Atomic models showing a $\mathrm{S}$ vacancy moving one site to the right. A slight tilt is introduced in the model to show the two $S$ atoms. (c) Energy as a function of reaction coordinate for the $S$ vacancy migration pathway shown in (a) and (b). (d, e) Atomic models showing $S$ vacancy moving one site to the right, next to a Pt atom sitting in a $S$ vacancy site. A slight tilt is introduced in the model to show the two $S$ atoms. (f) Energy as a function of reaction coordinate for the $S$ vacancy migration pathway away from the Pt atom shown in (d) and (e). (g, h) Atomic models showing a Pt atom migrating to the $S$ vacancy site to its right. The $S$ vacancy is indicated by an orange circle. (c) Energy as a function of reaction coordinate for the $\mathrm{Pt}$ atom migration from one vacancy to the next by the pathway shown in $(\mathrm{g})$ and $(\mathrm{h})$.

slightly smaller binding energy $(5.74 \mathrm{eV})$ compared to that for Pt in a $S$ vacancy (S-sub, $6.08 \mathrm{eV})$.

These dynamics of $\mathrm{Pt}$ atom hopping between stable sites indicates that the $\mathrm{Pt}$ atoms find fresh $\mathrm{S}$ vacancy sites in the $\mathrm{MoS}_{2}$. The electron beam is known to induce $S$ vacancies in $\mathrm{MoS}_{2}$ even at a $60 \mathrm{kV}$ accelerating voltage, which is governed by the ionization damage rather than the knock-on mechanism, ${ }^{24}$ and may also be affected by the surrounding $\mathrm{Pt}$ atoms $^{25}$ (Table S1). These vacancies are mobile in the lattice, leading to assembly into line vacancy structures. ${ }^{24,26-28}$ Therefore, during the imaging in Figure 2, S vacancy sites are constantly being created and migrating. Consistent with existing literature, ${ }^{29}$ our calculated formation energy of a S vacancy is $6.87 \mathrm{eV}$, which is much higher than the binding energies of a $\mathrm{Pt}$ atom on top of pristine $\mathrm{MoS}_{2}$ and similar to those trapped at a $S$ vacancy. Hence, the high flexibility of $S$ atoms is likely to arise from the efficient energy transfer between electron beam and light atoms. ${ }^{30}$ On the basis of the inelastic model including exact relativistic kinematics, ${ }^{30}$ the maximum energies transferred from a $60 \mathrm{kV}$ electron to $\mathrm{S}$, Mo, and $\mathrm{Pt}$ atoms are 4.35, 1.45, and $0.71 \mathrm{eV}$, which provides sufficient energies for $\mathrm{S} / \mathrm{Pt}$ diffusion and explains the relatively slow $S$ ejection observed in experiments.

In Figure 6, DFT calculations demonstrate the role of $S$ vacancy migration on the $\mathrm{Pt}$ stability. Figure $6 \mathrm{a}-\mathrm{c}$ show a 2.3 $\mathrm{eV}$ energy barrier for $\mathrm{S}$ vacancy migration, and in Figure $6 \mathrm{~d}-\mathrm{f}$ the barrier remains similar, even though a $\mathrm{Pt}$ atom is located next to the $S$ vacancy site. This indicates that there is no preference for $\mathrm{S}$ vacancies to migrate next to $\mathrm{Pt}$ atoms in $\mathrm{MoS}_{2}$. However, the presence of a $S$ vacancy next to a $\mathrm{Pt}$ atom in a $1 \mathrm{~S}$ vacancy site lowers its energy barrier for hopping to the next site to $0.75 \mathrm{eV}$, which is considerably less than the $\sim 3 \mathrm{eV}$ required for $\mathrm{Pt}$ to migrate to the surface sites in Figure 5. This indicates that $\mathrm{S}$ vacancy migration to sites next to $\mathrm{Pt}$ atoms in $1 \mathrm{~S}$ vacancy sites will enhance the migration dynamics of the $\mathrm{Pt}$ atoms across the $\mathrm{MoS}_{2}$.

The presence of surface amorphous carbon on top of $\mathrm{MoS}_{2}$ also plays an important role in the relative structure of $\mathrm{Pt}: \mathrm{MoS}_{2}$. Strong $\mathrm{Pt}-\mathrm{C}$ bonding impacts the intrinsic $\mathrm{Pt}: \mathrm{MoS}_{2}$ interactions and leads to a wide range of positions adopted by the $\mathrm{P}$ atom relative to the $\mathrm{MoS}_{2}$ lattice. Figure 7a shows a single $\mathrm{Pt}$ atom located in a region of $\mathrm{MoS}_{2}$ with significant 


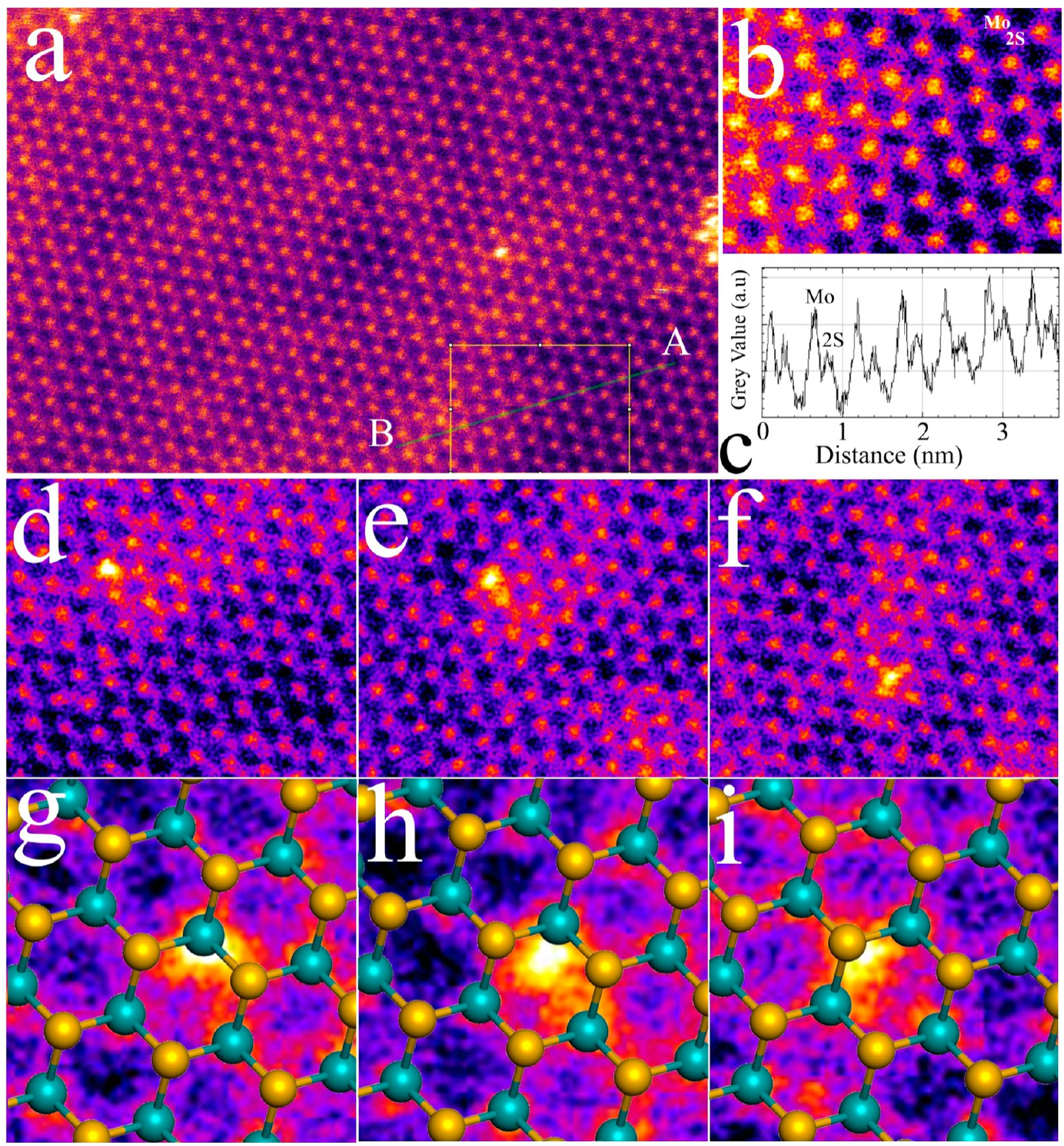

Figure 7. Pt atoms in regions of $\mathrm{MoS}_{2}$ with surface carbon contamination. (a) ADF-STEM image (false color LUT "fire") showing a single Pt atom in a contaminated region of $\mathrm{MoS}_{2}$. (b) Magnified view of the region indicated in (a) with the yellow box, showing the interface between the clean and contaminated area. (c) Line profile of intensity as a function of distance along the line indicated in green in (a), from A-B. Mo and $2 S$ columns are indicated and a rising background is seen in the presence of the amorphous carbon surface layer. (d-f) Series of ADFSTEM images showing the dynamics of a single Pt atom. ( $\mathrm{g}-\mathrm{i})$ Overlay of $\mathrm{MoS}_{2}$ atomic positions with the ADF-STEM images in (d)-(f), respectively, showing the $\mathrm{Pt}$ atom is randomly located with respect to the Mo and $\mathrm{S}$ sites.

surface carbon. The yellow box shows the boundary between the clean $\mathrm{MoS}_{2}$ on the right and the contaminated region to the left. A line scan of the intensity from the ADF-STEM image, Figure $7 c$, shows a steady increase in the background level after $1 \mathrm{~nm}$ going from pristine to the area containing the carbon. This increase in background signal from the carbon indicates thicker regions. Figure $7 \mathrm{~d}-\mathrm{i}$ show a series of ADF-STEM images of the dynamics of the $\mathrm{Pt}$ atom in Figure $7 \mathrm{a}$, with the $\mathrm{Pt}$ changing its relative position with respect to the $\mathrm{MoS}_{2}$ lattice across the three frames. The coordination of the $\mathrm{Pt}$ atom is random and is mainly dictated by the bonding in the carbon.
Figure 8a shows an atomic model of monolayer $\mathrm{MoS}_{2}$ with a small surface region of amorphous carbon containing three $\mathrm{Pt}$ atoms (red). The ADF-STEM image simulation of the structure in Figure $8 \mathrm{a}$ is shown in Figure $8 \mathrm{~b}$, in which the contrast from the $\mathrm{Pt}$ atom dominates. A large region of higher contrast from the carbon layer is visible in Figure $8 \mathrm{~b}$, showing that at $60 \mathrm{kV}$ it is possible to differentiate the clean and carbon-containing regions, even down to a monolayer of carbon. A 3D perspective view, Figure 8c, of the atomic structure in Figure 8a shows the surface carbon layer on top of the $\mathrm{MoS}_{2}$. This amorphous carbon atomic model was constructed based on the information 


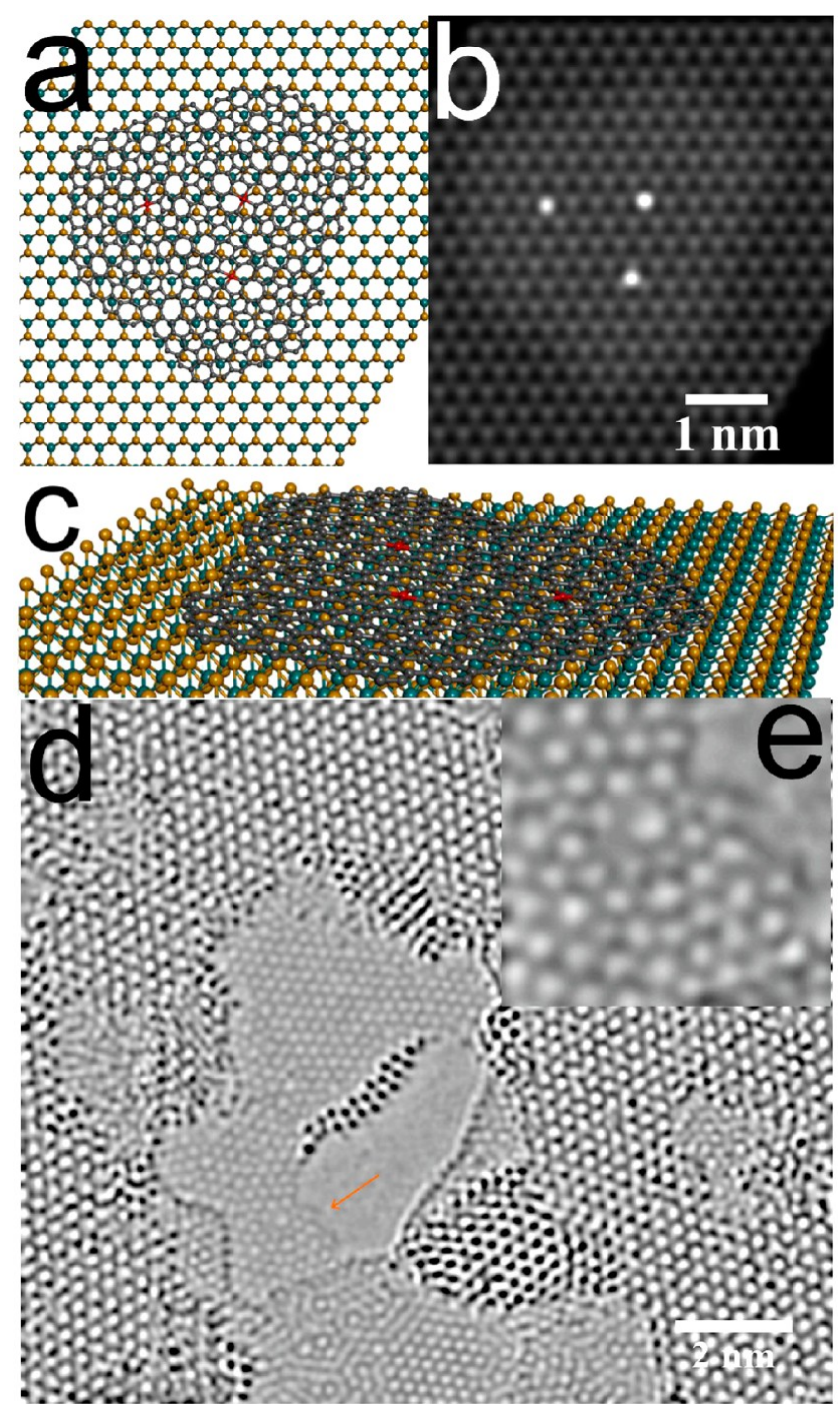

Figure 8. (a) Atomic model of $\mathrm{MoS}_{2}$ monolayer with an amorphous carbon layer on top with three Pt dopants (red) within the carbon layer. (b) ADF-STEM image simulation based on the atomic model in (a), showing three bright contrast spots associated with the single $\mathrm{Pt}$ atoms in carbon. (c) 3D perspective view of the atomic model from (a). (d) AC-TEM image of monolayer $\mathrm{MoS}_{2}$ after extensive electron beam irradiation to open up holes in the $\mathrm{MoS}_{2}$ and reveal the surface carbon layer. Orange arrow indicates the carbon region shown in higher magnification in (e).

gained from the AC-TEM image in Figure 8d, where prolonged electron beam irradiation was used to sputter away $\mathrm{MoS}_{2}$ to open holes and reveal the underlying carbon monolayer. The orange arrow in Figure 8d indicates the monolayer amorphous carbon that contains a combination of hexagons and nonhexagonal rings. A thicker bilayer region is found just below this arrow. Pt atoms are likely to be bonded either in-plane to the carbon structure or sitting on top of the defective area. The simulations in Figure $8 \mathrm{~b}$ are for $\mathrm{Pt}$ atoms bonded in-plane, as can be seen in more detail in Figure 9a-c.

The amorphous nature of the carbon layer means that $\mathrm{Pt}$ atoms within this layer are located at random distances with respect to other $\mathrm{Pt}$ atoms. This will lead to the relative position of $\mathrm{Pt}$ atoms with respect to the Mo and $\mathrm{S}$ atomic columns below to be also random. The atomic models and image simulations in Figures $9 \mathrm{~d}-\mathrm{i}$ show the variable position of $\mathrm{Pt}$ atoms and the resulting contrast in the image. This corresponds to images of contaminated areas of $\mathrm{MoS}_{2}$ with $\mathrm{Pt}$ atoms.

In order to understand the configuration dependence of catalytic activity induced by $\mathrm{Pt}$ atoms on $\mathrm{MoS}_{2}$ monolayers, we have estimated the hydrogen adsorption free energy $\left(\Delta G_{H}\right)$ using DFT simulations, which is highly correlated to the efficiency and has been successfully used as a descriptor for HER $^{31,32}$ Consistent with previous studies, ${ }^{14,33}$ our calculated $\Delta G_{\mathrm{H}}$ for Mo substituted by the $\mathrm{Pt}$ site and the $\mathrm{S}$ vacancy without $\mathrm{Pt}$ atoms are -0.00 and $-0.06 \mathrm{eV}$, respectively, much lower than that for the basal plane $(2.06 \mathrm{eV})$. A similar degree of improvement can be obtained by $\mathrm{Pt}$ doping in the Mo-top configuration $(0.03 \mathrm{eV})$, while S-top and V-top configurations are slightly less favorable, with $\Delta G_{\mathrm{H}}=0.20$ and $0.05 \mathrm{eV}$, respectively. In contrast to $\mathrm{Mo}$ substituted by $\mathrm{Pt}$, the surrounding $\mathrm{S}$ atoms remain inert, and the $\mathrm{H}$ atom tends to be adsorbed on the $\mathrm{Pt}$ atom in the Mo-top configuration (Figure 10c). If the $\mathrm{Pt}$ atom is trapped by a $\mathrm{S}$ vacancy, however, $\Delta G_{\mathrm{H}}$ substantially increases to $0.83 \mathrm{eV}$ (Figure 10a), and thus the catalytic center is deactivated. Such significant differences between structures with the same dopant atoms originate from the sensitivity of the $\mathrm{H}$ atom binding strength to the surrounding chemical environment, which determines both the energy level of hybridized states and their occupations. For a Pt atom trapped in a $\mathrm{S}$ vacancy, the hybridization shifts Ptoccupied orbitals toward the gap (Figure 10b), resulting in the relatively small binding energy. The opposite process occurs in the Mo-top configuration, wherein hybridization eliminates the relevant unoccupied orbitals while populating midgap states (Figure 10d), leading to stabilization of the entire system. Interestingly, our results suggest that while an individual $S$ vacancy or Pt dopant may serve as an active catalytic center, the presence of both will suppress activity and thus should be avoided when optimizing materials for HER.

The HER activity for a series of representative single-metal atoms was explored by virtual screening of $E_{\mathrm{b}}$ and $\Delta G_{\mathrm{H}}$ to provide general insights. In all situations, the $S$-sub configurations are energetically much more favorable than the others (Figure 10e), indicating that the metal atoms are prone to trapping by $S$ vacancies. In contrast, both the absolute value of $\Delta G_{\mathrm{H}}$ and the variation with different configurations strongly rely on the atom type (Figure 10f), which reflects the complexity arising from the hybridization between $\mathrm{H}$ and metal orbitals as well as the polarization induced by adjacent $S$ atoms. Such dependence is also distinct from that reported for the Mo substitution structure dictated by unsaturated $S$ atoms. ${ }^{14}$ In addition to confirming the superior performance of $\mathrm{Pt}$ atoms, the computational screening enables us to identify several candidates that may warrant future exploration. For example, $\mathrm{Au}, \mathrm{V}$, and $\mathrm{Zn}$ dopants may provide desirable catalytic activity even in S-sub configurations. For defect-free $\mathrm{MoS}_{2}$ sheets, $\mathrm{Ag} / \mathrm{Mn} / \mathrm{Cr} / \mathrm{Ti} / \mathrm{V}$ in Mo-top, $\mathrm{Cr}$ in S-top, and $\mathrm{Cr} / \mathrm{Cu}$ / $\mathrm{Mn} / \mathrm{V}$ in $\mathrm{V}$-top configurations may also serve as catalytic centers.

\section{CONCLUSIONS}

In summary, we have shown that isolated $\mathrm{Pt}$ atoms on pristine $\mathrm{MoS}_{2}$ monolayers are stabilized by bonding within $S$ vacancies. This increases the barrier for escape and localizes $\mathrm{Pt}$ atoms sufficiently long for atomic level ADF-STEM imaging. The electron beam causes hopping of $\mathrm{Pt}$ atoms to different $\mathrm{S}$ vacancy sites created by the electron beam. A different behavior is observed when $\mathrm{Pt}$ atoms are surrounded by carbon, in 


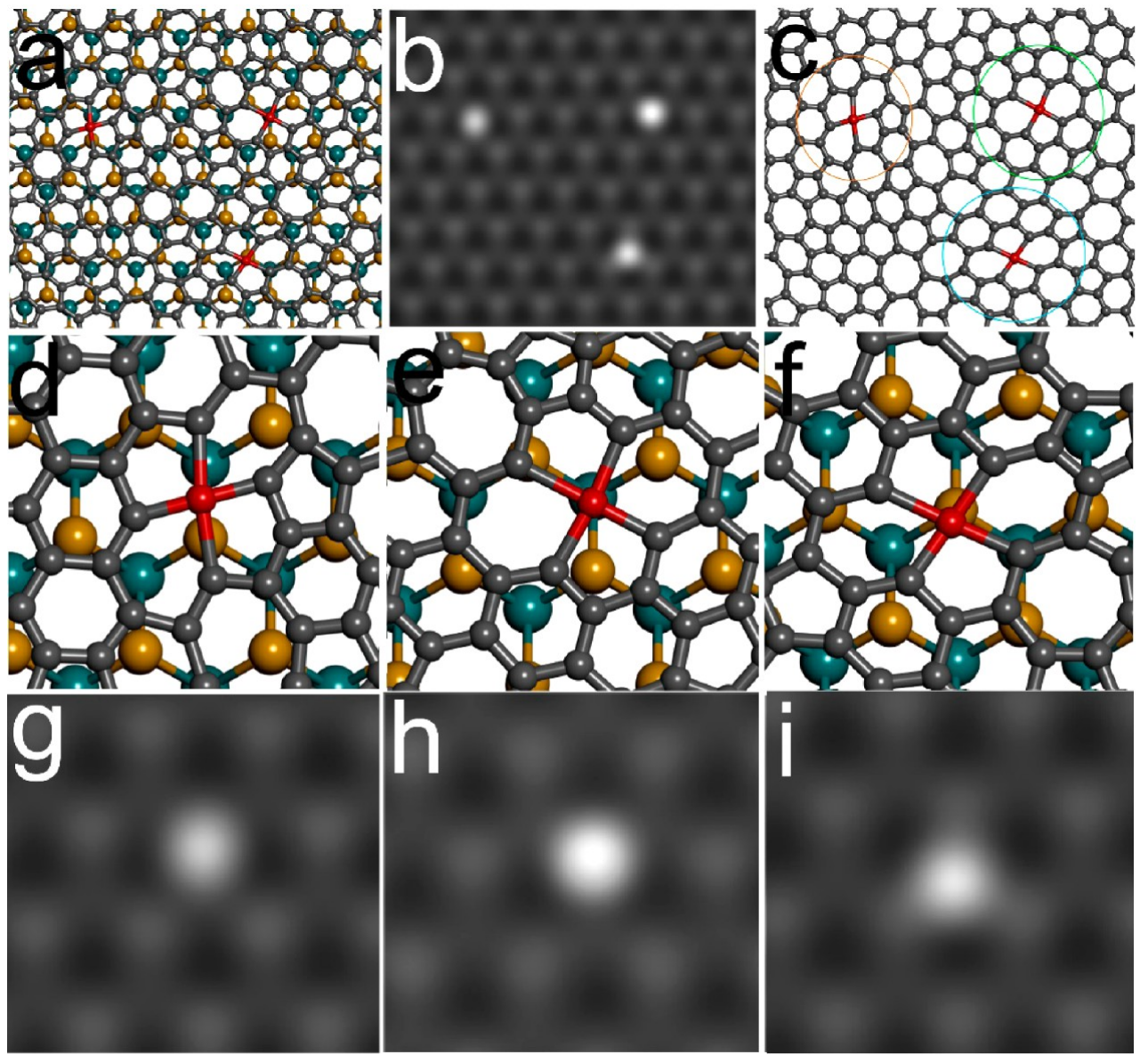

Figure 9. (a) Magnified view of the atomic model from Figure 7a, showing three Pt atoms bound within the carbon monolayer. (b) Magnified view of the ADF-STEM image simulation from Figure $7 \mathrm{~b}$, corresponding to the atomic model in (a). (c) Atomic model from (a), but with the $\mathrm{MoS}_{2}$ removed to show the position of $\mathrm{Pt}$ atoms in the carbon film. Circles indicate the location of Pt atoms. (d-f) Magnified view of the atomic model in (a) for Pt atom (red) sites indicated by the colored circles in (c) for (d) orange, (e) green, and (f) blue, respectively. (g-i) ADF-STEM image simulations corresponding to the atomic structures in $(\mathrm{d})-(\mathrm{f})$ respectively.

particular where a thin amorphous layer of carbon is found on the $\mathrm{MoS}_{2}$. This layer most likely arises from the polymer transfer process and is very difficult to completely remove, as is established for graphene. However, hydrocarbons are also likely to adsorb to the $\mathrm{MoS}_{2}$, and hence its role should always be considered when determining the structure of elements bound to the $2 \mathrm{D}$ material surface. The filling of $\mathrm{S}$ vacancies by $\mathrm{Pt}$ atoms has a detrimental effect on the surface catalytic activity for HER. The high mobility of Pt across the pristine surface of $\mathrm{MoS}_{2}$ indicates that unbound $\mathrm{Pt}$ atoms detaching from larger $\mathrm{Pt}$ nanoclusters may get trapped in these vacancy sites.

\section{METHODS/EXPERIMENTAL}

Synthesis and Transfer of Monolayer $\mathrm{MoS}_{2} \cdot \mathrm{MoS}_{2}$ monolayers were synthesized by a hydrogen-free CVD method using molybdenum trioxide $\left(\mathrm{MoO}_{3}, \geq 99.5 \%\right.$, Sigma-Aldrich) and sulfur (S, $\geq 99.5 \%$, Sigma-Aldrich) powder as precursors, as reported previously. ${ }^{34}$ The growth was conducted under atmospheric pressure with the carrier gas of argon, and $\mathrm{SiO}_{2} / \mathrm{Si}\left(300 \mathrm{~nm}\right.$ thick $\left.\mathrm{SiO}_{2}\right)$ chips were used as substrates. To avoid cross-contamination between $\mathrm{MoO}_{3}$ and $\mathrm{S}$ during the reaction, an inner tube with a smaller diameter was applied to load $\mathrm{MoO}_{3}$, which separated it from the $\mathrm{S}$ powder placed in the outer $1 \mathrm{in}$. quartz tube. Two furnaces were used to give a better temperature control of both precursors and the substrate. The typical heating temperatures for $\mathrm{S}, \mathrm{MoO}_{3}$, and $\mathrm{SiO}_{2} / \mathrm{Si}$ substrates were set to be $\sim 180$, $\sim 300$, and $\sim 800{ }^{\circ} \mathrm{C}$, respectively. After growth, monolayer $\mathrm{MoS}_{2}$ was transferred onto a $\mathrm{Si}_{3} \mathrm{~N}_{4}$ TEM grid (Agar Scientific AG21580). It was then spin-coated with a thin film of PMMA on the $\mathrm{MoS}_{2} / \mathrm{SiO}_{2} / \mathrm{Si}$ substrate surface, followed by floatation on a $1 \mathrm{~mol} / \mathrm{L}$ potassium hydroxide $(\mathrm{KOH})$ solution to etch the $\mathrm{SiO}_{2}$. Once the PMMA/MoS film was detached from the Si substrate, it was transferred to deionized water several times to remove residuals left by the etchant. Subsequently, the PMMA/MoS ${ }_{2}$ film was transferred onto a holey $\mathrm{Si}_{3} \mathrm{~N}_{4}$ TEM grid, air-dried overnight, and baked at $180{ }^{\circ} \mathrm{C}$ for $15 \mathrm{~min}$. The PMMA scaffold was finally removed by submerging the TEM grid in acetone for $8 \mathrm{~h}$.

Sample Preparation of Pt-Doped Monolayer $\mathrm{MoS}_{2}$. After transferring $\mathrm{MoS}_{2}$ single layers to a $\mathrm{Si}_{3} \mathrm{~N}_{4}$ TEM grid, one drop of 0.025 $\mathrm{mol} / \mathrm{L}$ hexachloroplatinic acid $\left(\mathrm{H}_{2} \mathrm{PtCl}_{6}\right)$-ethanol solution was deposited onto the $\mathrm{MoS}_{2}$ surface and dried in air. The sample was subsequently placed in a 1 -in. quartz tube and heated to $350{ }^{\circ} \mathrm{C}$ for 15 min with argon used as the carrier gas, which decomposed $\mathrm{H}_{2} \mathrm{PtCl}_{6}$ to Pt. After the reaction, the sample was rapidly cooled by being removed from the hot zone furnace.

Scanning Transmission Electron Microscopy and Image Processing. Room-temperature ADF-STEM imaging was conducted using an aberration-corrected JEOL ARM300CF STEM equipped with a JEOL ETA corrector ${ }^{35}$ operated at an accelerating voltage of $60 \mathrm{kV}$ located in the Electron Physical Sciences Imaging Centre (ePSIC) at Diamond Light Source. Dwell times of $5-20 \mu$ s and a pixel size of $0.006 \mathrm{~nm} \mathrm{px}^{-1}$ were used for imaging. Optical conditions used a CL aperture of $30 \mu \mathrm{m}$, a convergence semiangle of $31.5 \mathrm{mrad}$, a beam current of $44 \mathrm{pA}$, and inner-outer acquisition angles of 49.5-198 mrad. 
a

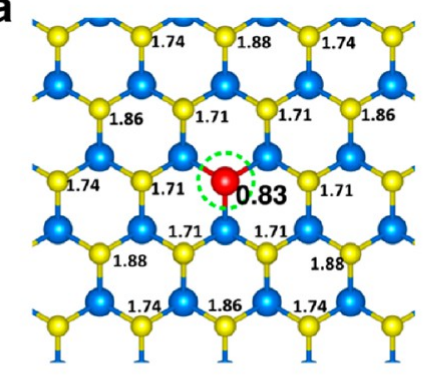

C

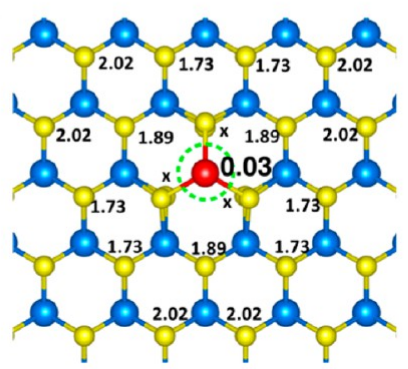

b

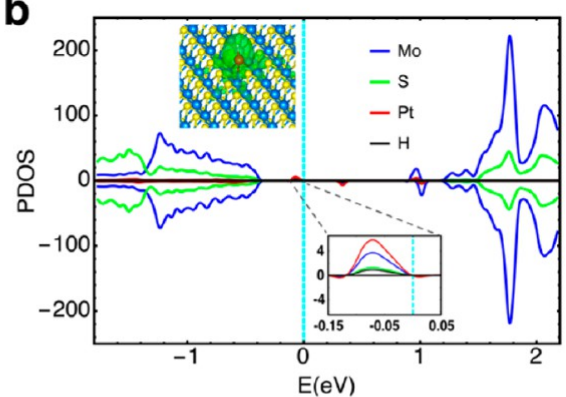

d

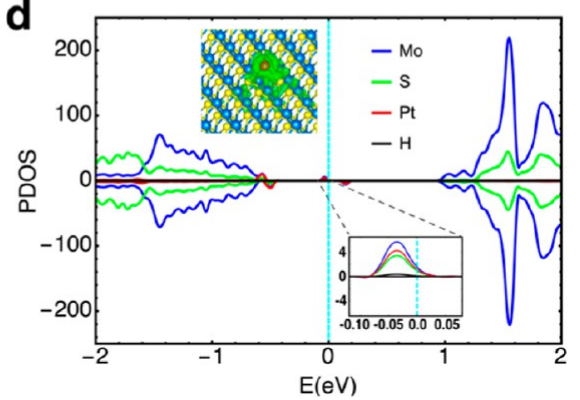

e

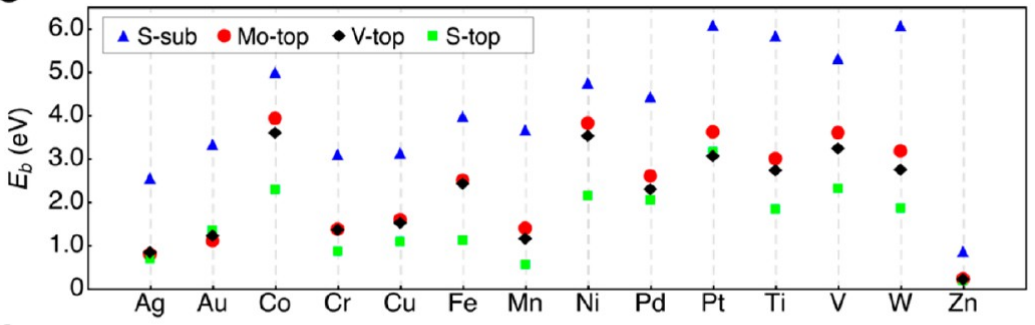

f

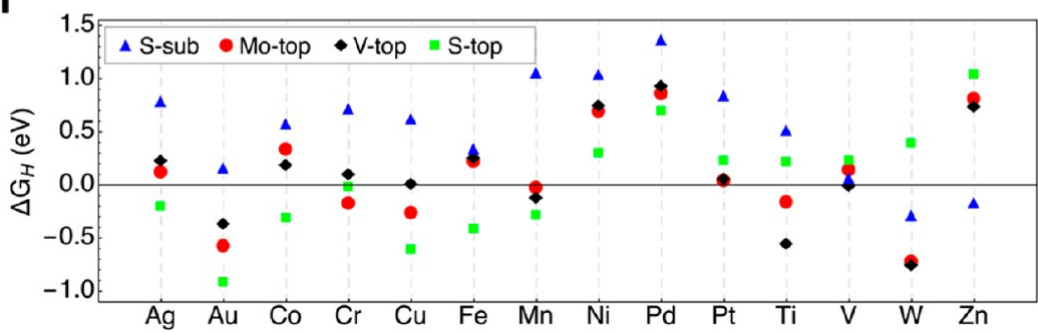

Figure 10. Calculated catalytic properties for Pt-doped $\mathrm{MoS}_{2}$ in various configurations. Hydrogen adsorption free energy $\left(\Delta G_{\mathrm{H}}\right)$ in units of eV for (a) S-sub and (c) Mo-top configurations. The green dashed circle highlights the active site for HER, while " $\mathrm{x}$ " means unable to bind $\mathrm{H}$. Panel (b) and (d) show the spin-dependent projected density of states (PDOS) for S-sub and Mo-top configurations, respectively, with the Fermi level illustrated by the cyan dashed line. The wave function and detailed PDOS of the states relevant to the binding strength of $H$ atoms are shown in the inset. (e) Binding energy $\left(E_{\mathrm{b}}\right)$ and (f) $\Delta G_{\mathrm{H}}$ for a series of metal atom dopants in S-sub, M-top, V-top, and S-top configurations.

Images were processed using the ImageJ software. A fire false color LUT was applied to grayscale images for visual enhancement. Atomic models were generated by using Accelrys Discovery Studio Visualizer. Multislice HAADF image simulations based on the corresponding atomic models were carried out using the JEMS software with parameter settings adjusted to match the experimental conditions.

Reaction Path Calculation. Standard $a b$ initio simulations within the framework of DFT, as implemented in the Vienna Ab Initio Simulation Package (VASP v5.4), ${ }^{36}$ were performed to explore the reaction paths for diffusion of $\mathrm{Pt}$ and $\mathrm{S}$ atoms on the $\mathrm{MoS}_{2}$ monolayer. Plane-wave and projector-augmented-wave (PAW) type pseudopotentials were employed, ${ }^{37}$ with kinetic-energy cutoffs set to $300 \mathrm{eV}$. The GGA-PBE functional ${ }^{38}$ was used to describe the exchangecorrelation interactions, while the van der Waals effects were accounted for by the DFT-D2 method of Grimme, ${ }^{39}$ with a $50 \AA$ cutoff radius for pair interactions. The $8 \times 4$ rectangular supercells containing 192 atoms along with a $15 \AA$ vacuum perpendicular to the sheet were constructed to prevent artificial interactions between periodic images. The minimum energy paths were determined by the climbing image nudged elastic band (CI-NEB) ${ }^{40}$ method with 5-7 images. Only the $\Gamma$ point was sampled, and the force tolerance for convergence was set to $0.03 \mathrm{eV} / \AA$.

Catalytic Activity for HER. The catalytic activities of a range of metal atom dopants in different configurations were investigated by evaluating the adsorption free energy $\left(\Delta G_{\mathrm{H}}\right)$, adopting an approach described in previous studies: ${ }^{41}$

$$
\Delta G_{\mathrm{H}}=E\left(\mathrm{MoS}_{2}+\mathrm{H}\right)-E\left(\mathrm{MoS}_{2}\right)-E\left(\mathrm{H}_{2}\right) / 2+0.24 \mathrm{eV}
$$

where $E\left(\mathrm{MoS}_{2}+\mathrm{H}\right)$ and $E\left(\mathrm{MoS}_{2}\right)$ are the energies of pristine or doped $\mathrm{MoS}_{2}$ with and without an adsorbed $\mathrm{H}$ atom, $E\left(\mathrm{H}_{2}\right)$ is the energy of a hydrogen molecule, and the term $0.24 \mathrm{eV}$ accounts for the changes in zero-point energy and entropy at standard conditions. ${ }^{41}$ The structures were relaxed until all forces were smaller than $0.05 \mathrm{eV} /$ $\AA$. Only the $\Gamma$ point was used for geometric optimization, while a Monkhorst-Pack ${ }^{42}$ k-point grid of $4 \times 4 \times 1$ and Gaussian smearing of $0.024 \mathrm{eV}$ were applied to calculate the density of states. 
The dependence of our predictions on an exchange-correlation functional has been examined by Pt-doped $\mathrm{MoS}_{2}$ using a smaller $6 \times 3$ supercell. The binding energies of a Pt atom at sites of S-sub, Mo-top, S-top, and V-top are predicted to be $6.22,3.48,3.10$, and $2.89 \mathrm{eV}$ with the HSE06 hybrid functional, ${ }^{43}$ while those obtained by the PBE functional are $6.09,3.59,3.09$, and $3.03 \mathrm{eV}$, respectively. The values of $\Delta G_{\mathrm{H}}$ in these configurations calculated with the HSE06 functional $(0.99,0.22,0.12,0.22 \mathrm{eV})$ are also consistent with those obtained with the PBE functional $(0.83,0.04,0.20,0.05 \mathrm{eV})$, verifying that our approach is sufficient for qualitatively predicting the structural and catalytic properties.

\section{ASSOCIATED CONTENT}

\section{S Supporting Information}

The Supporting Information is available free of charge on the ACS Publications website at DOI: 10.1021/acsnano.7b00796.

Additional ADF-STEM images of Pt atoms in the clean and carbon contamination regions; ADF-STEM images and EDX of Pt nanoclusters on $\mathrm{MoS}_{2}$; image simulations for $\mathrm{Pt}$ atoms with different configurations; analysis of ADF-STEM images to show $\mathrm{Pt}$ atoms in $1 \mathrm{~S}$ and $2 \mathrm{~S}$ vacancies; table of $S$ vacancy formation energies affected by $\mathrm{Pt}$ atoms (PDF)

\section{AUTHOR INFORMATION}

\section{Corresponding Authors}

*E-mail (J. C. Grossman): jcg@mit.edu.

*E-mail: Jamie.warner@materials.ox.ac.uk.

\section{ORCID}

Shanshan Wang: 0000-0003-3750-6737

Jamie H. Warner: 0000-0002-1271-2019

\section{Author Contributions}

${ }^{\perp} \mathrm{H}$. Li and S. Wang contributed equally.

\section{Notes}

The authors declare no competing financial interest.

\section{ACKNOWLEDGMENTS}

J.H.W. thanks the Royal Society for support. S.W. thanks the CSC for support. H.L. thanks ExxonMobil for financial support. This research used resources of the National Energy Research Scientific Computing Center, a DOE Office of Science User Facility supported by the Office of Science of the U.S. Department of Energy under Contract No. DE-AC0205CH11231.

\section{REFERENCES}

(1) Deng, D.; Novoselov, K. S.; Fu, Q.; Zheng, N.; Tian, Z.; Bao, X. Catalysis with Two-Dimensional Materials and Their Heterostructures. Nat. Nanotechnol. 2016, 11, 218-230.

(2) Wang, H.; Wang, Q.; Cheng, Y.; Li, K.; Yao, Y.; Zhang, Q.; Dong, C.; Wang, P.; Schwingenschlögl, U.; Yang, W.; Zhang, X. X. Doping Monolayer Graphene with Single Atom Substitutions. Nano Lett. 2012, 12, 141-144.

(3) Zhang, K.; Feng, S.; Wang, J.; Azcatl, A.; Lu, N.; Addou, R.; Wang, N.; Zhou, C.; Lerach, J.; Bojan, V.; Kim, M. J.; Chen, L.-Q.; Wallace, R. M.; Terrones, M.; Zhu, J.; Robinson, J. A. Manganese Doping of Monolayer $\mathrm{MoS}_{2}$ : The Substrate Is Critical. Nano Lett. 2015, 15, 6586-6591.

(4) Yun, W. S.; Lee, J. D. Unexpected Strong Magnetism of $\mathrm{Cu}$ Doped Single-Layer $\mathrm{MoS}_{2}$ and Its Origin. Phys. Chem. Chem. Phys. 2014, 16, 8990-8996.

(5) Robertson, A. W.; Montanari, B.; He, K.; Kim, J.; Allen, C. S.; Wu, Y. A.; Olivier, J.; Neethling, J.; Harrison, N.; Kirkland, A. I.;
Warner, J. H. Dynamics of Single Fe Atoms in Graphene Vacancies. Nano Lett. 2013, 13, 1468-1475.

(6) Ma, D.; Ju, W.; Li, T.; Zhang, X.; He, C.; Ma, B.; Lu, Z.; Yang, Z. The Adsorption of $\mathrm{CO}$ and $\mathrm{NO}$ on the $\mathrm{MoS}_{2}$ Monolayer Doped with $\mathrm{Au}, \mathrm{Pt}, \mathrm{Pd}$, or Ni: A First-Principles Study. Appl. Surf. Sci. 2016, 383, 98-105.

(7) Chen, Q.; Robertson, A. W.; He, K.; Gong, C.; Yoon, E.; Kirkland, A. I.; Lee, G.-D.; Warner, J. H. Elongated Silicon-Carbon Bonds at Graphene Edges. ACS Nano 2016, 10, 142-149.

(8) Cao, C.; Wu, M.; Jiang, J.; Cheng, H. P. Transition Metal Adatom and Dimer Adsorbed on Graphene: Induced Magnetization and Electronic Structures. Phys. Rev. B: Condens. Matter Mater. Phys. 2010, $81,205424$.

(9) Chan, K. T.; Neaton, J. B.; Cohen, M. L. First-Principles Study of Metal Adatom Adsorption on Graphene. Phys. Rev. B: Condens. Matter Mater. Phys. 2008, 77, 235430.

(10) Cong, W. T.; Tang, Z.; Zhao, X. G.; Chu, J. H. Enhanced Magnetic Anisotropies of Single Transition-Metal Adatoms on a Defective $\mathrm{MoS}_{2}$ Monolayer. Sci. Rep. 2015, 5, 9361.

(11) Zhang, X.; Lu, Z.; Xu, G.; Wang, T.; Ma, D.; Yang, Z.; Yang, L. Single Pt Atom Stabilized on Nitrogen Doped Graphene: CO Oxidation Readily via the Tri-Molecular Eley-Rideal Mechanism. Phys. Chem. Chem. Phys. 2015, 17, 20006-20013.

(12) Qiao, B.; Wang, A.; Yang, X.; Allard, L. F.; Jiang, Z.; Cui, Y.; Liu, J.; Li, J.; Zhang, T. Single-Atom Catalysis of CO Oxidation Using $\mathrm{Pt}_{1} /$ $\mathrm{FeO}_{\mathrm{x}}$. Nat. Chem. 2011, 3, 634-641.

(13) Cheng, N.; Stambula, S.; Wang, D.; Banis, M. N.; Riese, A.; Xiao, B.; Li, R.; Sham, T.-K.; Liu, L.; Botton, G. A.; Sun, X. Platinum Single Atom and Cluster Catalysis of the Hydrogen Evolution Reaction. Nat. Commun. 2016, 7, 13638.

(14) Deng, J.; Li, H.; Xiao, J.; Tu, Y.; Deng, D.; Yang, H.; Tian, H.; Li, J.; Ren, P.; Bao, X. Triggering the Electrocatalytic Hydrogen Evolution Activity of Inert Two-Dimensional $\mathrm{MoS}_{2}$ Surface via SingleAtom Metal Doping. Energy Environ. Sci. 2015, 8, 1594-1601.

(15) Dai, X.; Du, K.; Li, Z.; Liu, M.; Ma, Y.; Sun, H.; Zhang, X.; Yang, Y. Co-Doped $\mathrm{MoS}_{2}$ Nanosheets with the Dominant CoMoS Phase Coated on Carbon as an Excellent Electrocatalyst for Hydrogen Evolution. ACS Appl. Mater. Interfaces 2015, 7, 27242-27253.

(16) Krivanek, O. L.; Chisholm, M. F.; Nicolosi, V.; Pennycook, T. J.; Corbin, G. J.; Dellby, N.; Murfitt, M. F.; Own, C. S.; Szilagyi, Z. S.; Oxley, M. P.; Pantelides, S. T.; Pennycook, S. J. Atom-by-Atom Structural and Chemical Analysis by Annular Dark-Field Electron Microscopy. Nature 2010, 464, 571-574.

(17) Warner, J. H.; Lin, Y.; He, K.; Koshino, M.; Suenaga, K. Stability and Spectroscopy of Single Nitrogen Dopants in Graphene at Elevated Temperatures. ACS Nano 2014, 8, 11806-11815.

(18) Lin, Y. C.; Teng, P. Y.; Yeh, C. H.; Koshino, M.; Chiu, P. W.; Suenaga, K. Structural and Chemical Dynamics of Pyridinic-Nitrogen Defects in Graphene. Nano Lett. 2015, 15, 7408-7413.

(19) Lin, Y. C.; Dumcenco, D. O.; Komsa, H.-P.; Niimi, Y.; Krasheninnikov, A. V.; Huang, Y.-S.; Suenaga, K. Properties of Individual Dopant Atoms in Single-Layer $\mathrm{MoS}_{2}$ : Atomic Structure, Migration, and Enhanced Reactivity. Adv. Mater. 2014, 26, 28572861.

(20) Robertson, A. W.; Lin, Y.; Wang, S.; Sawada, H.; Allen, C. S.; Chen, Q.; Lee, S.; Lee, G.; Han, S.; Yoon, E.; Kirkland, A. I.; Kim, H.; Suenage, K.; Warner, J. H. Atomic Structure and Spectroscopy of Single Metal (Cr, V) Substitutional Dopants in Monolayer $\mathrm{MoS}_{2}$. ACS Nano 2016, 10, 10227-10236.

(21) Singh, N.; Schwingenschlögl, U. A Route to Permanent Valley Polarization in Monolayer $\mathrm{MoS}_{2}$. Adv. Mater. 2017, 29, 1600970.

(22) Chen, Q.; He, K.; Robertson, A. W.; Kirkland, A. I.; Warner, J. H. Atomic Structure and Dynamics of Epitaxial 2D Crystalline Gold on Graphene at Elevated Temperatures. ACS Nano 2016, 10, 1041810427.

(23) Zhou, W.; Zou, X.; Najmaei, S.; Liu, Z.; Shi, Y.; Kong, J.; Lou, J.; Ajayan, P. M.; Yakobson, B. I.; Idrobo, J. C. Intrinsic Structural Defects in Monolayer Molybdenum Disulfide. Nano Lett. 2013, 13, 26152622. 
(24) Zan, R.; Ramasse, Q. M.; Jalil, R.; Georgiou, T.; Bangert, U.; Novoselov, K. S. Control of Radiation Damage in $\mathrm{MoS}_{2}$ by Graphene Encapsulation. ACS Nano 2013, 7, 10167-10174.

(25) Ramasse, Q. M.; Zan, R.; Bangert, U.; Boukhvalov, D. W.; Son, Y. W.; Novoselov, K. S. Direct Experimental Evidence of Metalmediated Etching of Suspended Graphene. ACS Nano 2012, 6, 40634071.

(26) Wang, S.; Lee, G.-D.; Lee, S.; Yoon, E.; Warner, J. H. Detailed Atomic Reconstruction of Extended Line Defects in Monolayer $\mathrm{MoS}_{2}$. ACS Nano 2016, 10, 5419-5430.

(27) Komsa, H.-P.; Kurasch, S.; Lehtinen, O.; Kaiser, U.; Krasheninnikov, A. V. From Point to Extended Defects in TwoDimensional $\mathrm{MoS}_{2}$ : Evolution of Atomic Structure under Electron Irradiation. Phys. Rev. B: Condens. Matter Mater. Phys. 2013, 88, 35301.

(28) Komsa, H.-P.; Kotakoski, J.; Kurasch, S.; Lehtinen, O.; Kaiser, U.; Krasheninnikov, A. V. Two-Dimensional Transition Metal Dichalcogenides under Electron Irradiation: Defect Production and Doping. Phys. Rev. Lett. 2012, 109, 35503.

(29) Komsa, H. P.; Kotakoski, J.; Kurasch, S.; Lehtinen, O.; Kaiser, U.; Krasheninnikov, A. V. Two-dimensional Transition Metal Dichalcogenides under Electron Irradiation: Defect Production and Doping. Phys. Rev. Lett. 2012, 109, 035503.

(30) Garcia, A.; Raya, A. M.; Mariscal, M. M.; Esparza, R.; Herrera, M.; Molina, S. I.; Scavello, G.; Galindo, P. L.; Jose-Yacaman, M.; Ponce, A. Analysis of Electron Beam Damage of Exfoliated MoS2 Sheets and Quantitative HAADF-STEM Imaging. Ultramicroscopy 2014, 146, 33-38.

(31) Greeley, J.; Mavrikakis, M. Alloy Catalysts Designed from First Principles. Nat. Mater. 2004, 3, 810-815.

(32) Tsai, C.; Abild-Pedersen, F.; Nørskov, J. K. Tuning the $\mathrm{MoS}_{2}$ Edge-Site Activity for Hydrogen Evolution via Support Interactions. Nano Lett. 2014, 14, 1381-1387.

(33) Li, H.; Tsai, C.; Koh, A. L.; Cai, L.; Contryman, A. W.; Fragapane, A. H.; Zhao, J.; Han, H. S.; Manoharan, H. C.; AbildPedersen, F.; Norskov, J. K.; Zheng, X. L. Activating and Optimizing MoS2 Basal Planes for Hydrogen Evolution through the Formation of Strained Sulphur Vacancies. Nat. Mater. 2015, 15, 48-53.

(34) Wang, S.; Wang, X.; Warner, J. H. All Chemical Vapor Deposition Growth of $\mathrm{MoS}_{2}$ :h-BN Vertical van Der Waals Heterostructures. ACS Nano 2015, 9, 5246-5254.

(35) Hosokawa, F.; Sawada, H.; Kondo, Y.; Takayanagi, K.; Suenaga, K. Development of Cs and Cc Correctors for Transmission Electron Microscopy. Microscopy 2013, 62, 23-41.

(36) Kresse, G.; Furthmüller, J. Efficient Iterative Schemes for $A b$ Initio Total-Energy Calculations Using a Plane-Wave Basis Set. Phys. Rev. B: Condens. Matter Mater. Phys. 1996, 54, 11169-11186.

(37) Blochl, P. E. Projector Augmented-Wave Method. Phys. Rev. B: Condens. Matter Mater. Phys. 1994, 50, 17953-17979.

(38) Perdew, J. P.; Burke, K.; Ernzerhof, M. Generalized Gradient Approximation Made Simple. Phys. Rev. Lett. 1996, 77, 3865-3868.

(39) Grimme, S. Semiempirical GGA-Type Density Functional Constructed with a Long-Range Dispersion Correction. J. Comput. Chem. 2006, 27, 1787-1799.

(40) Henkelman, G.; Uberuaga, B. P.; Jónsson, H. A Climbing Image Nudged Elastic Band Method for Finding Saddle Points and Minimum Energy Paths. J. Chem. Phys. 2000, 113, 9901-9904.

(41) Nørskov, J. K.; Bligaard, T.; Logadottir, A.; Kitchin, J. R.; Chen, J. G.; Pandelov, S.; Stimming, U. Trends in the Exchange Current for Hydrogen Evolution. J. Electrochem. Soc. 2005, 152, J23-J26.

(42) Monkhorst, H. J.; Pack, J. D. Special Points for Brillouin-Zone Integrations. Phys. Rev. B 1976, 13, 5188-5192.

(43) Krukau, A. V.; Vydrov, O. A.; Izmaylov, A. F.; Scuseria, G. E. Influence of the Exchange Screening Parameter on the Performance of Screened Hybrid Functionals. J. Chem. Phys. 2006, 125, 224106. 